\title{
STUDIES IN TEMPERATURE SENSATION. III. THE SENSITIVITY OF THE BODY TO HEAT AND THE SPATIAL SUMMATION OF THE END ORGAN RESPONSES
}

\author{
By JAMES D. HARDY AND THEODORE W. OPPEL 1 \\ (From the Russell Sage Institute of Pathology in affiliation with the New York Hospital and \\ the Department of Medicine, Cornell University Medical College, New York City)
}

(Received for publication January 6, 1937)

It has long been known that the sensation produced by a heat stimulus of fixed intensity increases with the size of the area stimulated. The observations which have been made on this phenomenon are largely qualitative both as to the magnitude of the stimulus and the size of the stimulated area. Recent investigation of this subject has been made by Bazett and McGlone (3), and Bohnenkamp and Pasquay (4). The former measured the threshold stimulus of sensation for a single heat receptor as a rise in skin temperature of $0.3^{\circ} \mathrm{C}$. produced at a rate of $0.2^{\circ} \mathrm{C}$. per second, whereas, the threshold for the whole arm was estimated to be a rise of $0.1^{\circ} \mathrm{C}$. produced at the rate of $0.005^{\circ} \mathrm{C}$. per second. Bohnenkamp and Pasquay found a skin temperature rise of $1.8^{\circ} \mathrm{C}$. as the threshold of a single end organ and a rise of $0.4^{\circ} \mathrm{C}$. as that for a group of six endings. They discussed their results in terms of spatial summation and expressed their data in an exponential formula of the type of Mach's law of visual intensity discrimination. The nature of these experiments is such that the data are inadequate for a quantitative investigation of the relationship of heat sensation to the size and location of the stimulated area. The purpose of the present experiments is to obtain such data and further, to determine the smallest amount of radiation which can be perceived by the body as warmth.

\section{EXPERIMENTAL RESULTS}

In the present study three variables are considered, namely, the magnitude of the sensation, the strength of the stimulus, and the size and location of the area exposed. The variability of the first of these was eliminated by keeping the sensation constant, i.e., at the minimum value, thereby the relationship between the stimulus strength and the area stimulated could be investigated. The meth-

\footnotetext{
1 New York Hospital Research Fellow.
}

ods of measuring the minimal stimulus and of obtaining the proper sources of radiation have been described (7). Non-penetrating infra-red radiation was used throughout these experiments because it is invisible, it is more easily obtained in intensities uniform over large surfaces, and it is the radiation for which no corrections for reflection, etc., are necessary. The visible and the penetrating infra-red radiations were used for comparison on the forehead.

A comparison of the sensitivity of forehead areas of different size to visible, penetrating infrared, and non-penetrating infra-red radiation was first made. Starting with an area of $0.2 \mathrm{~cm}^{2}$, the area exposed to the radiation was increased by steps using circular apertures of larger diameters. The screens containing the apertures were arranged close to but not touching the skin surface so that normal heat loss from the skin was not affected; the largest circular aperture that could be used on the forehead was one with an area of $40 \mathrm{~cm}^{2}$. No care was taken to mark the particular skin area tested to insure the testing of the same spot each time, and it was not uncommon for the subject to move his head during an experiment. Thereby many locations on the forehead were tested with the same size area, and the results showed that the sensitivity of the forehead is effectively uniform over its surface. It was not possible to make observations with visible radiation over the whole range of areas because sufficient energy was not available for the small areas and with large areas it was practically impossible to prevent the subject's seeing the light. The sensation results from thermal changes in the skin and these changes are directly proportional to the intensity of the radiation (8). Therefore, in this discussion, the radiation rate is used as a quantitative estimate of stimulus strength. The values given are those for absorbed energy; that is, the incident energy has been corrected for reflection. 
TABLE I

Minimum stimuli in $\mathrm{gm}$. cal/ $/ \mathrm{cm}^{2} / \mathrm{sec}$. for various sized areas of the forehead for non-penetrating infra-red, penetrating infra-red, and visible light

\begin{tabular}{|c|c|c|c|c|c|c|c|c|c|}
\hline \multirow{2}{*}{ Area } & \multicolumn{3}{|c|}{$\begin{array}{c}\text { Non-penetrating } \\
\text { infra-red }\end{array}$} & \multicolumn{3}{|c|}{$\begin{array}{l}\text { Penetrating } \\
\text { infra-red }\end{array}$} & \multicolumn{3}{|c|}{ Visible } \\
\hline & $\begin{array}{c}\text { Sub- } \\
\text { ject } \\
\text { I }\end{array}$ & $\begin{array}{c}\text { Sub- } \\
\text { ject } \\
\text { II }\end{array}$ & $\begin{array}{c}\text { Aver- } \\
\text { age }\end{array}$ & $\begin{array}{c}\text { Sub- } \\
\text { ject } \\
\text { I }\end{array}$ & $\begin{array}{c}\text { Sub- } \\
\text { ject } \\
\text { II }\end{array}$ & $\begin{array}{l}\text { Aver. } \\
\text { age }\end{array}$ & 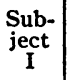 & $\begin{array}{c}\text { Sub- } \\
\text { ject } \\
\text { II }\end{array}$ & $\begin{array}{l}\text { Aver- } \\
\text { age }\end{array}$ \\
\hline $\begin{array}{l}c m . .^{2} \\
0.20\end{array}$ & \begin{tabular}{|l|}
.0205 \\
.0186 \\
\end{tabular} & .0189 & .0192 & & & & & & \\
\hline 0.95 & $\begin{array}{l}.0084 \\
.0087 \\
\end{array}$ & $\begin{array}{l}.0092 \\
.0065 \\
\end{array}$ & .0082 & $\begin{array}{l}.0157 \\
.0162 \\
\end{array}$ & .0158 & .0159 & & & \\
\hline 3.46 & \begin{tabular}{|l|}
.0028 \\
.0027 \\
.0030 \\
\end{tabular} & $\begin{array}{l}.0028 \\
.0030\end{array}$ & .0028 & .0059 & $\begin{array}{l}.0055 \\
.0050 \\
.0065\end{array}$ & .0057 & & & \\
\hline 7.08 & \begin{tabular}{|l|}
.0018 \\
.0019
\end{tabular} & $\begin{array}{l}.0018 \\
.0014 \\
.0015\end{array}$ & .0017 & $\begin{array}{l}.0027 \\
.0028\end{array}$ & .0026 & .0027 & $\begin{array}{l}.0035 \\
.0031 \\
.0036 \\
.0035 \\
.0036\end{array}$ & $\begin{array}{l}.0034 \\
.0036 \\
.0035 \\
.0035 \\
.0035\end{array}$ & .0035 \\
\hline 10.0 & $\begin{array}{l}.0014 \\
.0013 \\
\end{array}$ & $\begin{array}{l}.0011 \\
.0013\end{array}$ & .0013 & .0020 & .0020 & .0020 & & & \\
\hline 14.5 & .0008 & $\begin{array}{l}.0010 \\
.0009 \\
.0009\end{array}$ & .00095 & .0012 & $\begin{array}{l}.0012 \\
.0012\end{array}$ & .0012 & $\begin{array}{l}.0016 \\
.0016 \\
.0017 \\
.0018 \\
.0017\end{array}$ & .0017 & .0017 \\
\hline 23.8 & .0005 & $|.0006|$ & .0006 & \begin{tabular}{|l|}
.0008 \\
.0007 \\
.0007 \\
\end{tabular} & .0011 & .0009 & & & \\
\hline $\mathbf{4 0 . 0}$ & .0004 & $\begin{array}{l}.0004 \\
.0005\end{array}$ & .0004 & .0007 & .0008 & .0007 & & & \\
\hline
\end{tabular}

The results of tests on two white subjects with the three types of radiation stimuli are tabulated in Table I. Each value represents a complete test which usually included several individual trials. Column 1 of the table contains the size of the areas tested, Columns 2, 3 and 4 the corresponding amounts of radiation in $\mathrm{gm}$. $\mathrm{cal} / \mathrm{cm}^{2} / \mathrm{sec}$. which were required to produce a barely perceptible sensation of warmth. It will be noted that the per cent of variation in the individual determinations is about the same for all sizes of areas. The decrease in the amount of stimulus required to evoke sensation as the area irradiated is increased, confirms in a quantitative way the qualitative observations of previous workers.

As pointed out in an earlier paper (7), the difference in the stimulating power of these radiations depends on the manner in which the skin absorbs them: that is, the more penetrating the radiation the less effective it is in stimulating sensation. This difference is seen to exist for all areas on which comparisons were made, and the ratio of the stimulating energies is approximately the same for all the areas. It follows, therefore, that the number of end organs stimulated in any area is the same for all three types of radiation, and the penetrating radiations do not stimulate end organs which might be located at greater depths in the tissues any better than the nonpenetrating radiation. Histological evidence (1) indicates that temperature end organs may be distributed in the tissues at depths from $0.1 \mathrm{~mm}$. to $1 \mathrm{~mm}$. but they respond to heat stimuli as if depth were of no consequence. Anatomical evidence $(1,4)$ also points to a rather sparse distribution of end organs over the skin surface (i.e., one ending per sq. $\mathrm{cm}$. on the prepuce and forearm). End organ counts on the forehead were not made, but the evidence from heat measurements is that the sensitivity of the forehead, even for small areas, is nearly uniform from place to place. This would indicate either that the forehead is densely populated with receptors or that each end organ responds to stimulation over a considerable skin area. This latter possibility as well as the fact that penetration of radiation does not increase the number of end organs responding, supports the idea that the endings respond to the thermal changes occurring in a blood vessel network which forms a layer of high thermal conductivity under the skin surface. The venous and arterial plexuses of Spalteholtz probably represent such a layer.

The close analogy between such a system and the physicist's radiation thermopile is interesting. The usual type of radiation thermocouple has soldered to it a metal disc or radiation " receiver" which has considerably greater area than the thermocouple itself. In the same way, although the nerve ending be punctiform, the circulation of blood in its neighborhood forms a highly conducting " receiver" for heat stimuli.

Tests were made not only of the forehead area but of the whole of the face, the thorax, and the anterior body surface with non-penetrating infrared radiation. The size of the exposed areas was measured by taking the silhouette upon paper and determining the area either with a planimeter or by weighing. The back of the thorax and the entire posterior body surface were also tested. Except for the experiments on the whole body surface, the subjects were seated with only those 
TABLE II

Minimum stimuli for various sized areas on the body for non-penetrating infra-red radiation

\begin{tabular}{|c|c|c|c|c|c|c|}
\hline \multicolumn{2}{|c|}{ Area } & \multicolumn{3}{|c|}{$\begin{array}{l}\text { Minimum stimulus in } \\
\mathrm{gm} . \mathrm{cal} / \mathrm{cm}^{2} / \mathrm{sec} \text {. }\end{array}$} & \multicolumn{2}{|c|}{$\begin{array}{l}\text { Skin temperature } \\
\text { elevation }\end{array}$} \\
\hline Location & Size & jub- & ject II & $\begin{array}{l}\text { Aver- } \\
\text { age }\end{array}$ & Rate & 3 seconds \\
\hline Forehead & $\begin{array}{c}c m .2 \\
.20 \\
.95 \\
3.46 \\
7.08 \\
10.0 \\
14.5 \\
23.8 \\
40.0\end{array}$ & & & $\begin{array}{l}.0192 \\
.0082 \\
.0028 \\
.0017 \\
.0013 \\
.00095 \\
.0006 \\
.0004\end{array}$ & $\begin{array}{l}{ }^{\circ} C / \text { sec. } \\
0.16 \\
0.060 \\
0.021 \\
0.012 \\
0.009 \\
0.007 \\
0.004 \\
0.003\end{array}$ & \begin{tabular}{l}
\multicolumn{1}{c}{${ }^{\circ} C}$. \\
0.48 \\
0.18 \\
0.063 \\
0.036 \\
0.027 \\
0.0021 \\
0.013 \\
0.009
\end{tabular} \\
\hline Entire face & 197 & $\begin{array}{l}.00016 \\
.00024\end{array}$ & .00024 & .00021 & $0.001+$ & 0.004 \\
\hline $\begin{array}{l}\text { Face and } \\
\text { chest }\end{array}$ & $\begin{array}{l}1680 \text { (I) } \\
1940 \text { (II) }\end{array}$ & $\begin{array}{l}.00019 \\
.00016\end{array}$ & $\begin{array}{l}.00022 \\
.00025 \\
.00019\end{array}$ & .00019 & $0.001+$ & 0.004 \\
\hline $\begin{array}{l}\text { Back to } \\
\text { waist }\end{array}$ & $\begin{array}{l}1690 \text { (I) } \\
1940 \text { (II) }\end{array}$ & $\begin{array}{l}.00016 \\
.00016\end{array}$ & .00022 & .0002 & $0.001+$ & 0.004 \\
\hline $\begin{array}{l}\text { Anterior } \\
\text { body } \\
\text { surface }\end{array}$ & $\begin{array}{l}5440 \text { (I) } \\
5590 \text { (II) }\end{array}$ & $\begin{array}{l}.00013 \\
.00016 \\
.00013\end{array}$ & $\begin{array}{l}.00019 \\
.00016\end{array}$ & .00016 & $0.001-$ & $0.003-$ \\
\hline $\begin{array}{c}\text { Posterior } \\
\text { body } \\
\text { sırface }\end{array}$ & $\begin{array}{l}5440 \text { (I) } \\
5590 \text { (II) }\end{array}$ & $\begin{array}{l}.00013 \\
.00016\end{array}$ & $\begin{array}{l}.00013 \\
.00016\end{array}$ & .00015 & $0.001-$ & $0.003-$ \\
\hline $\begin{array}{c}\text { Forearm } \\
\text { and hand }\end{array}$ & $\left\{\begin{array}{l}360 \text { (I) } \\
420 \text { (II) }\end{array}\right.$ & $\begin{array}{l}.00019 \\
.00019\end{array}$ & .00028 & .00022 & $0.002-$ & 0.005 \\
\hline
\end{tabular}

parts exposed which were to be irradiated. For the largest areas the subjects stood nude before the source of radiation. In these experiments a battery of eight hot plates $(12 \mathrm{~cm}$. in diameter) mounted vertically $1 \mathrm{~cm}$. apart was used in order to obtain a more uniform distribution of radiation. The radiation varied about 5 per cent over the surface exposed. The results of the tests on two white subjects are given in Table II. The average data for the forehead are included in the table in order to give the entire range of areas studied. The last two columns give the temperature changes occurring at the skin surface during the irradiation. These temperature values are taken from the results of studies reported in Part II of this series (8). The sensation is always perceived after 3 seconds of irradiation and the total change in skin temperature is given in the last column. It is evident that Bazett's value of $0.1^{\circ} \mathrm{C}$. as the threshold temperature change for the entire arm is about twenty times too great and the value for the rate of rise about three times too great.

Table II reveals three facts in regard to the area-stimulus relationship. First, after a minimum stimulating energy as small as 0.0002 $\mathrm{cal} / \mathrm{cm}^{2} / \mathrm{sec}$. (or $0.001^{\circ} \mathrm{C}$. per second) has been reached, additional area affords no significant increase in sensitivity. This sensitivity is reached when relatively small areas of the body have been exposed such as the head, or the arms, or the chest, etc. Therefore, in ordinary circumstances of life when the body is fully clothed, the radiation sensitivity of the body is as high as it would be if the body were completely exposed. Second, the temperature sensitivity of the body is such that a sensation is evoked by a change in skin temperature of less than $0.003^{\circ} \mathrm{C}$., comparing favorably with the most delicate thermometers. The radiation sensitivity is not high compared to a high sensitivity, modern, vacuum thermopile which is sensitive to $10^{-12} \mathrm{cal} / \mathrm{cm}^{2} / \mathrm{sec}$., but compares well with the usual Rubens thermopile which is used in air. Third, as regards the sensitivity the location of an area on the body surface may be more important than its size; the average sensitivity of the face per cm. ${ }^{2}$ is more than twice that of the forearm and hand. This is an expected result as it is well known that certain parts of the body are more sensitive to heat stimuli than others.

The back and arm were tested and it was found that the areas were highly variable in sensitivity from place to place, and nothing could be made of the data without further knowledge of end organ distribution. The hand and forearm were care-

TABLE III

Minimum stimuli for various localities on forearm and back of hand with an exposed area of $23.8 \mathrm{~cm}^{2}$. Far infra-red stimulation

\begin{tabular}{c|c|c|c}
\hline \hline Area & Subject I & Subject II & Average \\
\hline Back of fingers & .00075 & .00084 & \\
& .00084 & .00110 & \\
& .00110 & .00081 & .00091 \\
\hline Back of hands & .00088 & .00075 & \\
(metacarples) & .0010 & .00085 & \multirow{2}{*}{.00088} \\
& .0011 & .0008 & .0009 \\
\hline Back of wrist & .0019 & .0019 & \\
& .0015 & .0019 & \\
& .0019 & .0017 & .0018 \\
\hline Back of forearm & .0022 & .0024 & \\
(10 cm. from wrist) & .0020 & .0025 & \multirow{2}{*}{.0027} \\
\hline Back of forearm & .0021 & .0023 \\
(5 cm. from elbow) & .0041 & .0045 & \\
& .0039 & .0046 & \\
& .0036 & .0042 & \multirow{2}{*}{0040} \\
& & .0035 & .0040 \\
\hline
\end{tabular}


fully studied and will serve to illustrate the situation. The sensitivity of the various localities on the forearm and hand was measured using one size of aperture and non-penetrating infra-red stimulation. The results are shown in Table III. The hand was found to be more than four times as sensitive as the proximal part of the forearm. The forearm was found to be progressively less sensitive nearer the elbow, suggesting a decreasing end organ population. Recognizing the presence of this variable, which was not significant when dealing with the forehead, tests were made by successively increasing the size of the area exposed. By means of a movable shutter the arm was gradually exposed by known amounts from the fingertips to the elbow and from the elbow to the fingertips. The results are shown in Table IV. Although the forearm and hand are

\section{TABLE IV}

Summation stimuli for forearm and back of hand

Direction of area increase: Fingertips to elbow

Distance from fingertip

\begin{tabular}{|c|c|c|}
\hline . & Area & Stimulatior \\
\hline $\mathrm{cm}$. & $\overline{c m .2}$ & \\
\hline 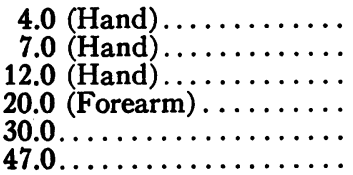 & $\begin{array}{r}20 \\
40 \\
100 \\
170 \\
240 \\
360\end{array}$ & $\begin{array}{l}.0013 \\
.00065 \\
.00053 \\
.00041 \\
.00029 \\
.00019\end{array}$ \\
\hline
\end{tabular}

Direction of area increase: Elbow to fingertips Distance from elbow

$\begin{array}{rrr}6.5 \text { (Forearm) } \ldots \ldots \ldots \ldots & 65 & .0015 \\ 9.5 \text { (Forearm) } \ldots \ldots \ldots \ldots & 100 & .0011 \\ 14.0 \text { (Forearm) } \ldots \ldots \ldots \ldots & 130 & .00069 \\ 22.5 \text { (Forearm) } \ldots \ldots \ldots \ldots & 190 & .00044 \\ 47.0 \text { (Fand) } \ldots \ldots \ldots \ldots \ldots & . \ldots 60 & .00019\end{array}$

not per unit of area as sensitive as the forehead, they combine to form an area which is nearly as sensitive as the whole body surface. Thus a paucity of end organs is made up for in large degree by the efficient combining of the separate effects of each end organ.

In order to test further the combining power or spatial summation of various portions of the body the following experiments were performed. Two square apertures $\left(25 \mathrm{~cm}^{2}\right.$ area, $3 \mathrm{~cm}$. apart) were so arranged that the skin areas placed behind them could be tested singly and together. The procedure was to test each aperture alone and then together. It was found that on the forehead the contiguity of the area did not affect the values of the stimuli. Thus, the right and left apertures gave identical values when stimulated separately; together they gave a value to be expected from the curve shown in Figure 1. Tests were then made on the backs of both hands, testing each hand separately and then both together. The same tests were made using as combination, the right side of the forehead and the back of the right hand. The results are shown in Table V.

TABLE V

Summation stimuli for various body areas

\begin{tabular}{|c|c|c|c|c|c|c|c|}
\hline \multicolumn{4}{|c|}{ Subject I } & \multicolumn{4}{|c|}{ Subject II } \\
\hline Left & Right & Both & $\underset{\text { tion }}{\text { Summa- }}$ & Left & Right & Both & $\underset{\text { tion }}{\text { Summa- }}$ \\
\hline \multicolumn{8}{|c|}{ BACKS OF HANDS } \\
\hline $\begin{array}{l}.0009 \\
.0008\end{array}$ & $\begin{array}{l}.0009 \\
.0008\end{array}$ & $\begin{array}{l}.0006 \\
.0006 \\
.0006 \\
.0006\end{array}$ & $\begin{array}{c}\text { per cent } \\
47\end{array}$ & .0012 & .0013 & .0008 & $\begin{array}{c}\text { per cent } \\
48\end{array}$ \\
\hline \multicolumn{8}{|c|}{ BACK OF RIGHT HAND AND FOREHEAD } \\
\hline $\begin{array}{l}\text { Fore- } \\
\text { head }\end{array}$ & Hand & Both & $\underset{\text { tion }}{\text { Summa- }}$ & $\begin{array}{l}\text { Fore- } \\
\text { head }\end{array}$ & Hand & Both & $\underset{\text { tion }}{\text { Summa- }}$ \\
\hline .0005 & .0011 & .0005 & 0 & .0006 & .0012 & .0006 & $\mathbf{0}$ \\
\hline
\end{tabular}

The sensitivity of both hands together was 47 per cent greater than either hand alone, although simultaneous stimulation of the hand and the forehead showed no increase in sensitivity over the forehead stimulated alone. This is evidence that spatial summation of heat sensation may have a value of zero and that the magnitude of the sensory effect is greatly dependent upon this factor. The close association of the hands suggests that habit may be important in the degree of sum-

TABLE VI

Summation values for forehead

\begin{tabular}{c|c|c|c|c}
\hline \hline Area & Stimulus & $\mathrm{A} \times \mathrm{I}$ & $\begin{array}{c}\text { Antilog } \\
(\log \mathrm{I}+.78 \log \mathrm{A})\end{array}$ & $\begin{array}{c}\text { Relative } \\
\text { summation }\end{array}$ \\
\hline cm.2 & cal/cm²/sec. & & & \\
0.95 & .0082 & .0078 & .0081 & per cent \\
3.46 & .0029 & .0097 & .0078 & 75 \\
7.08 & .0017 & .0120 & .0079 & 66 \\
10.0 & .0013 & .0130 & .0078 & 59 \\
14.5 & .0009 & .0138 & .0078 & 55 \\
23.8 & .0006 & .0143 & .0071 & .61 \\
40.0 & .0004 & .0160 & .0079 & 44 \\
\hline
\end{tabular}


mation which is attained between different parts of the body.

\section{DISCUSSION}

1. Subjective phenomena. Adescription of the impression reported by the subjects during stimulation of minimal sensation on the various exposed areas, is of assistance in interpreting the data. Stimulation of the small areas, less than $7 \mathrm{~cm}^{2}$, required so intense a rate of radiation that pain would result upon exposure of a large area to it. The minimal sensation for these small areas was more of a "hot" than a "warm" sensation. For the areas between $10 \mathrm{~cm}^{2}$ and $200 \mathrm{~cm}^{2}$ the sensation was that of a fleeting warmth lasting only a few seconds. At times the characteristic of "warmth" seemed to be 'lost, and the subject felt he was reporting a "change" of conditions rather than a feeling of warmth. For larger areas, the intensity of the sensation increased as the area is increased, and a definite feeling of warmth was perceived. When the minimum stimulus for the face was applied to the whole body surface the subject perceived a marked sensation of warmth, and it was always with some surprise that he found that he could not perceive a smaller rate of radiation. The area for which an intensity of $0.0002 \mathrm{cal} / \mathrm{cm}^{2} / \mathrm{sec}$. is the stimulus is in this sense a critical area, because for larger areas sensation is no longer minimal, and the minimal stimulus is constant.
2. Graphic analysis. Analysis of the data of Table II can be made by a graphical representation. A graph of the values in numerical coordinates is a curve of the type of an equilateral hyperbola and such a function is more easily handled in logarithmic coordinates. A plot of the data in terms of the logarithms of the area and stimulus is shown in Figure 1. The whole curve is definitely sigmoid although the portion from 1 to $40 \mathrm{~cm}^{2}$ on the forehead is a straight line. This form of curve is familiar to those studying visual sensation (6) and like the curve for visual acuity can be most easily studied in three parts: (I) the portion for very small areas (less than $1 \mathrm{~cm}^{2}$ ), (II) the portion which is a straight line, and (III) the portion for very large areas.

3. Lower portion of log curve (excitation threshold). The breaking of the log curve at the stimulus $0.0002 \mathrm{cal} / \overline{\mathrm{cm}^{2}} / \mathrm{sec}$. is strongly suggestive of the failure of some physiological process. The increase in sensation for large areas without increase in sensitivity shows that the summation process does not fail at this stimulus value. As a consequence, $0.00016 \mathrm{cal} / \overline{\mathrm{cm}^{2}} / \mathrm{sec}$. must represent the excitation threshold of the most sensitive heat receptors. Thus any greater intensity of stimulus will cause the end organs to respond and a stimulus smaller than this will evoke no effect regardless of area.

The region of Figure 1 may, on the basis of

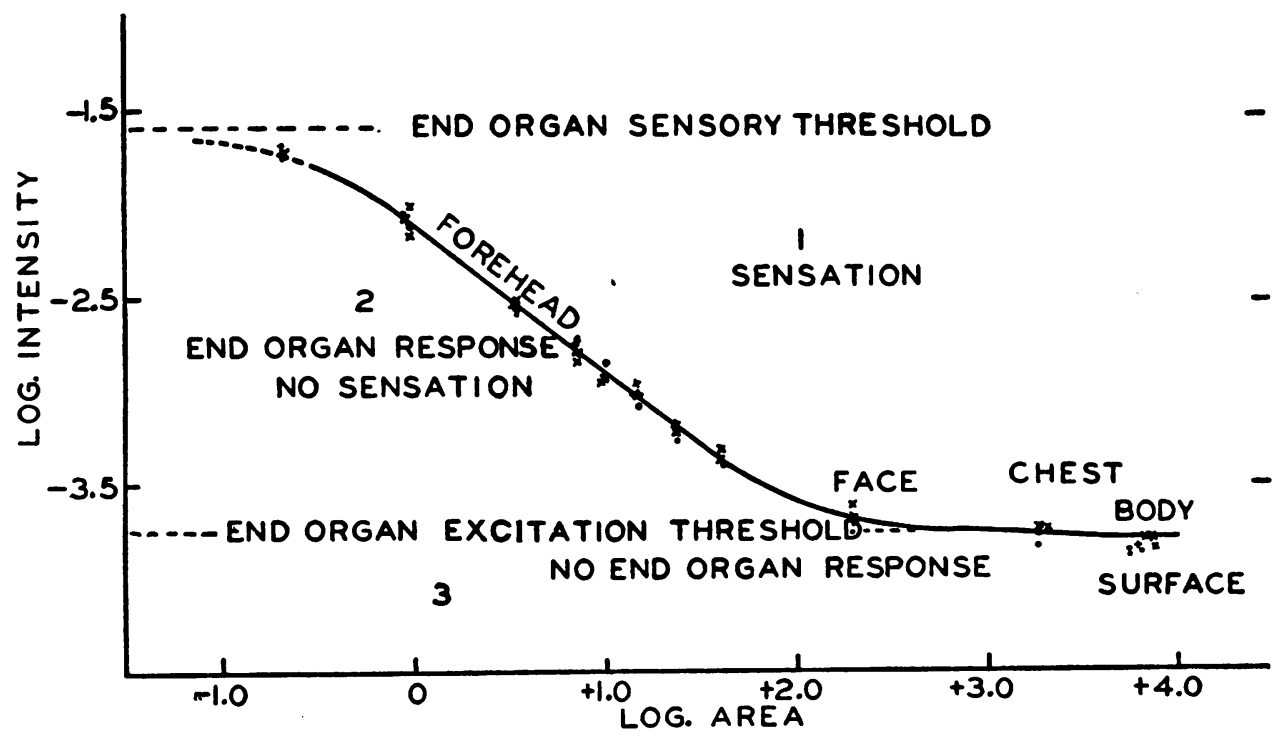

Fig. 1. Relationship of the Logarithms of Stimulus Intensity and Area Stimulated 
the above interpretation, be divided into three parts each having a physiologically different meaning. Area I, above the log curve, represents stimuli magnitude which will evoke sensation; areas II and III below the line refer to subthreshold sensory stimuli. In area III, below 0.00016 $\mathrm{cal} / \mathrm{cm}^{2} /$ sec. (log $\mathrm{I}=-3.79$ ), no end organ response is evoked, and in region II, above 0.00016 $\mathrm{cal} / \overline{\mathrm{cm}^{2}} / \mathrm{sec}$., end organs are responding but no sensory impression is made. The physiological effect of these unfelt impulses is not known at present.

4. Upper portion of log curve (sensory threshold). The breaking of the log curve for small areas and strong stimuli is an expected result. When an intensity of radiation has been reached which will evoke a sensation from one end organ, further decrease in area will require no increase in stimulus as long as the end organ remains in the irradiated field. Therefore, the intensity of stimulus for which the log curve again becomes parallel to the area axis is the threshold of sensation for a single receptor. This value cannot be accurately determined from the present data because very small areas were not tested. However, the value evidently lies between 0.031 and $0.025 \mathrm{cal} / \overline{\mathrm{cm}^{2}} / \mathrm{sec}$., corresponding to a temperature change of $0.16^{\circ} \mathrm{C}$. per second with a rise of $0.48^{\circ} \mathrm{C}$. in three seconds. These temperature values are in almost exact agreement with the measurements made with temperators on the prepuce by Bazett and McGlone (2). The area at which the break in the curve starts is $0.2 \mathrm{~cm} .{ }^{2}$ so that one may roughly estimate that one end organ is present in an area of about this size. The number of endings may be considerably larger if one takes into account the presence of receptors of higher threshold, and the above estimate would represent the minimum population.

5. The central portion of the log curve. The two parts of the log curve which have been discussed are those for which change in size of area stimulated caused no change in sensitivity. The straight line relationship between $\log$ intensity and $\log$ area, which is seen to be valid for the forehead is significant only when the special character of the forehead is considered. Over the forehead area the sensitivity of the skin per $\overline{\mathrm{cm}^{2}}$ is uniform, a condition we did not find on other parts of the body surface. On the basis that uniformity of sensitivity within this area means a nearly uniform distribution of heat end organs per $\overline{\mathrm{cm} .}{ }^{2}$, the data for this area can be partly analyzed. The data may be represented by the formula

$$
\text { 1. } \log \mathrm{I}+.78 \log \mathrm{A}=-2.09 \text {, }
$$

where $I=$ intensity of radiation, $A=$ area irradiated.

Thus, as the area stimulated is doubled the intensity is almost halved. The fact that the intensity does not decrease in exactly the same proportion as the number of available endings is increased is analogous to the multiple junction thermocouple. Due to increased resistance, the sensitivity of a thermopile does not double if the number of junctions is doubled. This falling off of sensitivity may be due to the progressive failure of the summation of the effects of the separate end organs or to a smaller number of end organs per unit area responding to the lowered intensity (6). The present experiments do not throw light on this matter.

Equation 1 is not the type of formula suggested by Bohnenkamp and Pasquay (4) and the present data cannot be fitted to their equation. However, their observations 'covered only six endings and are not directly comparable with these observations.

It is interesting to note the formal identity of Equation 1 with the formula for area and intensity found by Granit and Harper (5) when investigating spatial summation in the retina. Their equation is approximately

$$
\text { 2. } \log \mathrm{I}+\mathrm{c} \log \mathrm{A}=\text { constant. }
$$

6. Spatial summation. The ability to add the separate effects of end organs in widely distributed areas varies from zero, in case of the forehead and hand, to 47 per cent for the backs of the right and left hands. The summation within the forehead area is almost perfect. Impulses from different areas of the chest are added but the summation has not been quantitatively studied. Areas of poor sensitivity sum with areas of high sensitivity as has been shown for the forearm and hand. It would seem that summation depends to some extent upon habit and association, but the matter has not been completely investigated. 
That spatial summation is of prime importance in determining the intensity of heat sensation is clearly demonstrated. So far as our experiments go, no summation as high as 100 per cent has been observed and no clear examples of facilitation nor occlusion have been found.

7. Intensity discrimination. Intensity discrimination for heat sense has not been measured although it can be seen from the present experiments to be poor. The total range of intensities from end organ excitation threshold to pain is only 200 -fold. The magnitude of the variations $(\Delta I)$ in the measurements of the minimum stimuli over the range of intensities is proportional to the intensity ( $\mathrm{I})$. This is the type of relation which would be expected on the basis of a "Weber-Fechner" law for heat sensation, a relationship which might' be suspected from the similarity of the formula for vision and heat sense.

8. Sensitivity of body to heat. The temperature sensitivity of the body surface shown in Table II is evidence of the remarkable heat detector mechanism by which the internal temperature of the body is regulated. At the minimum perceptible rate of radiation the sensation is evoked usually after 3 seconds and the total rise in skin temperature under these circumstances is less than $0.003^{\circ} \mathrm{C}$. Such high sensitivity might be expected from the important part which the skin temperature plays in the normal loss of heat from the body surface. About 75 per cent of the heat produced in the body under comfortable circumstances depends upon the difference between the skin temperature and the surrounding temperature. A change of $1^{\circ} \mathrm{C}$. in the temperature of the walls alone, or 10 per cent in the normal radiation rate, air temperature, velocity, and humidity, etc., being constant, will evoke a subjective sensation in three seconds. The energy exchange in this process is of the order of one nine millionth of the normal hourly heat loss by radiation. That a sensation need not be necessary for this regulatory process is pointed out above, as the evidence shows that end organ responses may be going to the central nervous system, without evoking a sensation. These impulses may have connections with vasomotor pathways to the skin so that adjustment of internal thermal gradients can be made with a consequent decrease in end organ activity. In this way the surface temperature of the body could be adjusted to changing conditions without the sensory response reaching the level of awareness.

\section{SUMMARY AND CONCLUSIONS}

1. The sensory response produced by irradiation of a large range of areas of the body surface has been studied. The method allows stimulation of skin areas as large as the surface of the experimental subject and as small as desired. Tests were made of the minimum stimulating radiation rate for many parts of the body and for the body as a whole. Measurements were also made with radiations of different wavelengths.

2. For the whole range of intensities covered in this study the non-penetrating radiation was found to be more effective in stimulating sensation than the penetrating forms. The variation in depth of the end organs below the skin surface must therefore be unimportant as a factor in the thermal sensitivity.

3. The smallest rate of radiation which the body is capable of perceiving as warmth is 0.00015 gm. cal $/ \mathrm{cm}^{2} / \mathrm{sec}$. Sensation is evoked in $3 \mathrm{sec}-$ onds by exposure of $200 \mathrm{~cm}^{2}$ of surface to such a stimulus so that the total energy exchange for sensation is 0.09 gram cals. This amounts to one nine millionth of the normal hourly radiation loss from the body surface.

4. The skin temperature change caused by this radiation is a total elevation of $0.003^{\circ} \mathrm{C}$. produced at the rate of $0.001^{\circ} \mathrm{C}$. per second.

5. The intensity of the stimulus (rate of radiation) necessary to evoke sensation increases as the area stimulated is decreased, although in all cases the magnitude of the stimulus (total heat received) decreases as the area exposed decreases.

6. The forehead was found to be an area over which the sensitivity to radiation is uniform, thereby providing an ideal surface for investigating the area-intensity relationship. The intensity of radiation necessary to evoke minimal sensation when various sized areas on the forehead and on the anterior body surface were exposed was measured. The data were found susceptible to analysis in three parts:

$a$. The portion of the curve for low intensities is interpreted to mean the threshold of excitation 
of the most sensitive endings. This threshold is $0.00015 \mathrm{cal} / \overline{\mathrm{cm}^{2}} / \mathrm{sec}$.

$b$. The portion of the curve for high intensities is assumed to mark the threshold of sensation of the sensitive end organs. This value was not carefully measured but lies between 0.025 and $0.03 \mathrm{cal} / \overline{\mathrm{cm}^{2}} / \mathrm{sec}$.

c. The intermediate portion is a straight line obeying the formula: $\log \mathrm{I}+.78 \log \mathrm{A}=-2.09$. The similarity of the formula to the combined formulas for vision is pointed out.

7. The passage of impulses from end organs to the central nervous system without evoking sensation is demonstrated.

8. The importance of spatial summation on the magnitude of the sensory response is demonstrated. The present data are completely explained on the assumption that sensation intensity depends on the total frequency of impulses and upon summation.

9. The factors of summation 'and end organ distribution are shown to be highly variable for different parts of the body surface.

\section{BIBLIOGRAPHY}

1. Bazett, H. C., McGlone, B., Williams, R. G., and Lufkin, H. M., Sensation. I. Depth, distribution and probable identification in the prepuce of sensory end-organs concerned in sensations of temperature and touch; thermometric conductivity. Arch. Neurol. and Psychiat., 1932, 27, 489.

2. Bazett, H. C., and McGlone, B., Studies in sensation. II. The mode of stimulation of cutaneous sensations of cold and warmth. Arch. Neurol. and Psychiat., 1932, 27, 1031.

3. Bazett, H. C., and McGlone, B., Studies in sensation. III. Chemical factor in the stimulation of endorgan giving temperature sensations. Arch. Neurol. and Psychiat., 1932, 28, 71.

4. Bohnenkamp, H., and Pasquay, W., Das Verstarkungsgesetz Seine Beziehungen zum Machschen Kontrastgesetz. Untersuchungen zur Neuro-Physiologie und Pathologie. Deutsche Ztschr., f. Nervenh., 1932, 126, 138.

5. Granit, R., and Harper, P., Comparative studies on the peripheral and central retina. II. Synaptic reactions in the eye. Am. J. Physiol., 1930, 95, 211.

6. Hecht, S., The relation between visual acuity and illumination. J. Gen. Physiol., 1928, 11, 255.

7. Oppel, T. W., and Hardy, J. D., Studies in temperature sensation. I. A comparison of the sensation produced by infra-red and visible radiation. J. Clin. Invest., 1937, 16, 517.

8. Oppel, T. W., and Hardy, J. D., Studies in temperature sensation. II. The temperature changes responsible for the stimulation of the heat end organs. J. Clin. Invest., 1937, 16, 525. 